\title{
Trust in Nanotechnology? On Trust as Analytical Tool in Social Research on Emerging Technologies
}

\author{
Trond Grønli Åm
}

Received: 28 November 2010 / Accepted: 28 November 2010 /Published online: 19 December 2010

(C) The Author(s) 2010. This article is published with open access at Springerlink.com

\begin{abstract}
Trust has become an important aspect of evaluating the relationship between lay public and technology implementation. Experiences have shown that a focus on trust provides a richer understanding of reasons for backlashes of technology in society than a mere focus of public understanding of risks and science communication. Therefore, trust is also widely used as a key concept for understanding and predicting trust or distrust in emerging technologies. But whereas trust broadens the scope for understanding established technologies with well-defined questions and controversies, it easily fails to do so with emerging technologies, where there are no shared questions, a lack of public familiarity with the technology in question, and a restricted understanding amongst social researchers as to where distrust is likely to arise and how and under which form the technology will actually be implemented. Rather contrary, 'trust' might sometimes even direct social research into fixed structures that makes it even more difficult for social research to provide socially robust knowledge. This article therefore suggests that if trust is to maintain its important role in evaluating emerging technologies, the approach has to be widened and initially focus not on people's motiva-
\end{abstract}

T. G. Åm $(\bowtie)$

Department for Philosophy,

Norwegian University of Science and Technology,

Trondheim, Norway

e-mail: trond.am@ntnu.no tions for trust, but rather the object of trust it self, as to predicting how and where distrust might appear, how the object is established as an object of trust, and how it is established in relation with the public.

Keywords Co-production · Precautions · Prediction . Public understanding of nanotechnology $\cdot$ Social research in nanotechnology . Socially robust knowledge · Surveys · Trust · Trustworthiness

\section{Introduction: The Role of Trust in Upstream Engagement}

'Now thinking about nanotechnology: Nanotechnology involves working with atoms and molecules to make new particles that are used in cosmetics to make better anti-aging creams, suntan oils for better protection against skin cancer and cleaning fluids to make the home more hygienic. Despite these benefits, some scientists are concerned about the unknown and possibly negative effects of nanoparticles in the body and in the environment.'

-Introduction to Respondents in Eurobarometer's Survey [10].

Over the past decades, trust has become one of the core concepts in the literature on risk governance and 
communication of risk [2, 41]. Trust and an increased understanding of public opinions regarding particular technologies are considered to be important in order to avoid public protests that could arise because of these technologies-similar to biotechnology in Europe or nuclear and chemical technologies in the United States $[13,19,40]$. Since certain sociologists, like for example Ulrich Beck and Anthony Giddens [3, 12], began focusing on the concept of trust as relevant for our understanding of changes in society due to technological advances, understanding and fostering of trust have been seen as key factors in grasping the changing relationship between society in general and technology. Trust is then considered not only as an analytical tool, but also as a prerequisite for cooperation in all its variations, and as a social lubricant necessary for stability, prediction and normative integration (Misztal [31]:10, Poortinga and Pidgeon [37]). Therefore, analyzing public understanding of technology in the light of trust should also strengthen the development of a sound scientific practice, one that is in accordance with public opinion.

Among the several explorations into the backlashes in relation to technology, two key reasons for the lack of confidence have been suggested: 1) That public confidence in scientific advice to government has been undermined by a series of badly-handled technological controversies, for example surrounding nuclear power, genetically modified foods and the BSE scandal, and 2) that there is an ambiguity and unease about scientific advances running ahead of both public awareness and control [2].

Thus a need arises - both from the perspective of science and the public - to establish new models of thinking about the relationship between science and society that can serve all stakeholders. Because technology development often happens outside established democratic channels, with unknown risks and ambiguity regarding the stakeholders involved, a lack of public codetermination arises. Social research can compensate for this deficiency by mediating between the scientific community and the public when technology is implemented in society. Nowotny, Scott and Gibbons coined their influential notion of socially robust, or contextsensitive, knowledge [11, 34-36] to address this need for new models of thinking. They claim that reliable knowledge can only be achieved by including social knowledge and through an increased sensibility to the concrete and local environments in which the technology is implemented. Therefore, they see the involvement of social scientists in science policy as increasingly important in the successful implementation of technological innovations in society.

The notion of social robustness is important because it corresponds to the double analytical function of the concept 'trust'. Early studies on trust in relation to public understanding of technology maintain very much the same focus as Nowotny, Scott and Gibbons, namely to challenge the so called deficit model [46]. The model is built on the widely held assumption that public distrust in technology is due to a lack of or misinterpreted information. Although it seems likely that some distrust is due to such a deficit, the first deficit model challengers argued that many other social factors are also at stake when the scientific community is involved with the lay public. Science is not communicated to the public according to a one-to-one model. Values are at stake, as is trust in expertise, decision making and local knowledge. In his study on the sheep farmers in Cumbria facing restrictions due to radioactivity allegedly stemming from Chernobyl [47], Brian Wynne shows how scientists fail to gain the farmers' trust due to a lack of such contextual knowledge. Not only the scientists ignored local knowledge that would have made them aware that the radioactivity actually came from the nuclear reprocessing complex Sellafield. They also recommended the farmers to let their lambs graze in the valley, assuming that its improved grass would flush the radioactivity more quickly, ignoring the farmers knowledge that intensive grazing on this sparse resource could have long term damaging consequences.

Trust is seen not only as the consequence of a successful communication of science in public, that is, the goal of this focus is not just to convince the public of the safety of new technologies. Rather, an important precondition for such approaches is 'to engender and ensure public confidence and trust based on the inclusion of public concern in decision making' (Kearnes and Wynne [25]: 137).

Therefore Kearnes and Wynne's ([25]:134) commentary on the general shift in focus-from placing the problem in the public's lack of understanding to the public's lack of trust-is not an inaccurate description of the general social scientific approach 
to the controversies regarding the implementation of science and technology.

Trust is seen as as 'lubricating', that is, important to reestablishing the confident relationship between technological innovations and the public. But trust is also seen as an analytical tool for understanding social mechanisms around the implementation of new technology [37]. 'Trust' is better than 'understanding' because the former includes various factors that are relevant for good decisions. Not only it includes the kind of distinctive rationality that Wynne observed in Cumbria and that would not be targeted thorugh the lenses of scientific knowledge alone. Other kinds of motivations for trust might be relevant in the context of a conflict or the implementation of a given technology. Such an analysis should help those involved in technology development to ensure the implementation of socially robust and trustworthy science.

Based on these experiences, trust has become one of several important approaches in upstream engagement, by which lay people are included in advisory discussions on emerging technologies from an early stage, related to emerging technologies. Today it is commonly agreed by authorities, as well as stakeholders, that such engagement is important [30]. Early engagement provides the opportunity for lay people to add new perspectives and knowledge, such as local knowledge. This may lead not only to better decisions being made by experts and decision makers [45], but also, procedurally, the consultation of the public makes technology more socially legitimate. Hereby one assumes that the many controversies that follow with the broadening of new technology can be avoided.

In this article I aim to study how the concept of trust is being used in upstream engagement related to the emerging field of nanotechnologies. The question is whether the use of the concept of trust provides the dimensions of "social robustness" it is supposed to. My claim is that this is not the case. Unlike studies where controversies are established and motivations for trust might provide a richer understanding for understanding and predicting distrust, studies on lay attitudes regarding nanotechnology adopt the structures of previous experiences in a way that directs and fixes the analyses. Thus they sometimes fail to establish a relevant understanding of the problem in question, and social research risk to become irrelevant or simply failing to provide the interaction between lay public and the science community in developing sound scientific practices. The central argument of this article is that if trust is to remain an important tool in social research upon emerging technologies, it has to problematize the structures according to which it operates. This can be done through a study of theories on trust, but also by a different approach regarding nanotechnology; namely to focus on the concept 'nanotechnology' it self and how it will or will not be established as a possible object of trust.

\section{Nanotechnology and Public Engagement}

The emergence of nanotechnology already caught the attention of social research at its very beginning. Learning from the public's negative reception of genetically modified products (GM), especially in Europe, there has been a broad interest in developing nanotechnology in close dialogue with lay people and scholars. Numerous authoritative reports, such as the independent British report from the Royal Society and Royal Academy of Engineering from 2004 [38], draw attention to the importance of the social dimensions of nanotechnology and have thus contributed to setting the standard. This report focused particularly on the public's understanding of nanotechnology in a way that adds to the purely perceptive level, that is, how people think and feel about nanotechnology. Integrating public understanding is supposed to make a difference with regard to how nanotechnologies are developed and regulated; a point that has broad consensus amongst leading scholars doing research in the area. ${ }^{1}$ This is fully in accordance with the idea of socially robust knowledge. It is therefore particularly important that the information retrieved from studies on lay attitudes is of such a character that it might actually provide the grounds for making such a difference. Is this the case with nanotechnology?

In this article I have chosen to focus primarily on surveys. Firstly because they are widely used in trying to determine the emerging relationship people have with nanotechnology. Secondly I find it reasonable to believe that surveys, with their easy access to simplified opinions from a large group of people, have greater political influence than other approaches.

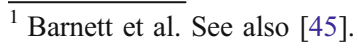


A number of studies on lay attitudes towards nanotechnology have appeared in recent years. ${ }^{2}$ Broadly speaking, the main conclusion is that the "new GM" has not materialized. People in general support nanotechnology, especially for medical research and renewable energy, whereas they tend to be more skeptical about who controls the technology and want more research that can ensure that applications are safe. Americans are generally more positive to nanotechnology than Europeans. At the same time, people still-roughly 10 years after the first surveys were conducted-know little about nanotechnology. More than half of the respondents in the recently published Eurobarometer had not even heard about it (Gaskell et al. [10]:22).

Despite the efforts and the somewhat promising results, one can question whether the findings actually help to develop the kind of 'socially robust knowledge' they are supposed to. Rather, my claim is that the use of surveys in measuring public trust in nanotechnology doo not provide the substantial knowledge intended, and additionally helps to confuse and blur both the role and the significance of public engagement in nanotechnology.

My critique is centred around three points: First of all, there is lack of familiarity with nanotechnology. it is therefore difficult to know what expressed opinions are actually expressions of. Secondly, there is a lack of clarity with the concept nanotechnology it self. The definition of nanotechnology is contested, and so is its function. It is still unclear whether nanotechnology is a new scientific paradigm or a research strategy. Combined with different definitions of nanotechnology, it is unclear to which extent-if at all'nanotechnology' will actually remain the concept around which our understanding of the underlying technologies will relate to. In combination with the missing familiarity with nanotechnology, this causes unclarity regarding expressed opinions as well as the object the opinions are supposed to relate to. Thirdly, this questions the role of social engagement, because the two previous points make it unclear which function and role the social engagement has. If they

\footnotetext{
${ }^{2}$ See for example [24], The Royal Academy and Royal Academy of Engineering Report, more surveys from Woodrow Wilson Center in Washington, Nature Nanotechnology and Eurobarometer.
}

are not able to provide analytical material that can enlighten the efforts of establishing a socially robust development of nanotechnology, their function might be reduced into mere consumer analysis to the benefit of commercial interests.

\section{Facing Vagueness in Upstream Engagement: How Social Research Fails to Legitimate its Role}

Recent surveys show that compared to other kinds of technology, many find it difficult to understand and to relate to the many instruments, products and research areas that are comprised under the label nanotechnology. In this respect, the concept simply lacks clarity [42]. Some have tried to compensate for this by calling for more involvement by lay people in the evaluation of concrete applications of nanotechnology. Thus it should be easier-at least potentially - to relate to the everyday life of the respondents and avoid nanotechnology being just an abstract concept. $[10,20]$. This is in line with interpretations of the experiences with GM, where one finding was that 'moral concerns attach specifically to particular applications and not necessarily to underlying molecular biology techniques' [16]. But this interpretation and approach is contested. ${ }^{3}$

For a long time, the problem has been people's general lack of familiarity with nanotechnology and thus it is difficult to know what the survey questions are actually measuring when 'opinions' are expressed. In addition there has been a general tendency among surveys to address people's concerns within a quite broad space of 'advantages' and 'risks'. Such framings might fit well into risk assessment and regulatory work, but it is far from sure that the same can be said with regards to how people's attitudes are reflected. Surveys conducted on GM clearly showed that such generalisations are insufficient when it comes to catching people's 'real' attitudes towards biotechnological applications [15].

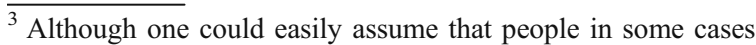
find it easier to relate to particular applications of technology that influence their daily lives, still some technologies, like GM, are politically and socially shaped in a way that makes the generic understanding of the entire technology influential for the understanding of all the specific applications subordinated to the generic label.
} 
Public attitude surveys tend to force people to adopt 'attitudes' to a given technology while they simultaneously ignore the factors that lead to the creation of these attitudes [24].

To compensate for these shortenings, several surveys have tried to incorporate various aspects that have proven to be important in shaping people's attitudes towards nanotechnology. For example, more recent work has taken the so called 'cultural cognition hypothesis', which tries to see the connection between people's convictions and their attitudes towards technology, as a starting point. Generally, perceptions of risks are often tightly related to other factors, such as political values, a relationship that would not appear unless specifically examined. Amongst the findings is the fact that people with more 'egalitarian' views tend to be more negative towards nanotechnology than people with a more 'individualistic' political orientation. This is also mirrored in the way they conceive risk: A more egalitarian person tends to perceive risks as more serious than an 'individualist', even when provided with more information [22]. Further analytical improvements, like the meta-analytical approach to surveys, where results from independent studies are aggregated into statistical overviews, provide even more nuanced knowledge for better understanding and mapping of public perceptions of risk related to nanotechnology [21, 40].

The question is to what extent or in which sense elaborating people's motivations or grounds for trust or distrust is relevant for determining the meaning of nanotechnology in public.

Indeed, perspectives on motivations, power and vulnerability structures related to trusting relations are relevant for understanding mechanisms of trust and distrust (see for example Grimen [14], Cook et al. [4], Hardin [17]). And this is also the reason why Kearnes and Wynne above are talking about a shift in focus from 'understanding' to 'trust', because the latter, by studying risk perception involving other factors than pure scientific analysis, provides richer grounds for understanding such mechanisms. With 'trust' we incorporate important factors that would not have been included with 'understanding'. But then it is important to bear in mind that this shift has happened in a context of already established conflicts, and is not necessarily valid for upstream engagement operating with several unknown factors.
On the contrary a study of motivations for 'trust' in 'nanotechnology' might blur the fact that many of the methods used in social research with nanotechnology, like focus groups, consensus conferences, surveys and citizen juries, draw upon earlier experiences in areas where there are well-defined questions concerning products or practices that directly influence the people involved.

Several commentators criticize surveys for distorting double- or multifaceted meanings by forcing people to answer within categories that are, in the worst case, totally irrelevant to them. Even when relevant, this type of study is often not suitable to reflect nuances in meaning or ambivalence in people's attitudes [2].

Sarah Davies et al. [5] criticize the ways social research creates certain structures that force people to answer particular questions so that the way questions are posed, directs research results. Even though surveys bring an even richer understanding of certain kind of motivations for trust or distrust in technology, it is not evident what these motivations refer to. In fact, this is even more complicated because what is true for using the concept 'nanotechnology' is also valid for 'trust'. What does it mean to trust? What do different actors intend to express if they say they trust a technology? How strong these motivations are, if they are of any consequence in people's factual future relationship with nanotechnology, or if people could take precautions against nanotechnology even if they wanted to. Some survey work also 'runs the risk of slipping back into understanding how public should relate to nanotechnology in terms of a deficit model, whether this is of knowledge or of trust' (Davies et al. [5] referring to Wynne).

Research into trust itself is trapped by its own frames when confronted by an object that is qualitatively different from earlier objects of study. While research into trust related to biotechnology arose in the context of controversies within the field, it is not clear at all with nanotechnology what actually the problem is. Although nanotechnology today could be said to be more than mere hype, given that there are already more than 1000 products on the market and even more in the pipeline, the modest familiarity with nanotechnology among the public still makes it appear vague and represents a challenge for the measuring of the public's understanding. 


\section{And What Kind of Object is Nanotechnology?}

One highly relevant question is whether it is likely to believe that the concept 'nanotechnology' could be the locus of such conflicts in the future at all. If we are in a situation of unfamiliarity, we can assume that increased familiarity and understanding of motivations will increase our understanding of people's attitudes, and hereby making us better suited for predicting grounds for trust or distrust. But this presupposes that the object in question is actually the right target for our analysis. Several factors indicate that this might not the case with 'nanotechnology':

In March 2006, the protective glass and bathroom sealant MagicNano was recalled in Germany, after causing severe breathing problems for some consumers [33]. The product was first labeled as nanotechnology but was later recalled and redefined following the negative attention that followed in the media. Although the Federal Institute for Risk Assessment in Berlin later concluded that the product contained no nanoparticles, it has been suggested that the nano label is so loosely defined that it is easy to avoid conflicts simply by redefining it [6]. As one of Matthew Kearnes et al.'s respondents expressed ([24]:39), '[I]f nanotechnology is going to be a bad word then let's call it something else'. This leads us naturally into a discussion around how committing the concept of nanotechnology is for those implementing technological products involving molecular technology, and which influence a low degree of commitment would have upon mechanisms of trust and distrust. The concept of nanotechnology is contested, and it is still unclear whether the term refers to a new scientific paradigm or simply a research strategy [26]. If the latter is assumed, it is not obvious that the term will stick to products if nanotechnology is conceived as something negative in public.

If this is the case, we risk - at least hypothetically - that efforts of determining and predicting trust are framed in a way that are actually not relevant for what is going on. If we determine people's 'trust' in 'nanotechnology', whereas the underlying technologies or applications are actually being implemented with a different name, or with no name at all-the entire effort might have been completely out of target and fails to find the shared question or problem to negotiate upon. Davies et al. write:

'At a more fundamental level, this and the question of problem definition highlight the essential performativity of public engagement on emerging technologies. While all engagement processes shape their participants into certain forms of citizens mobilised around certain kinds of issues [...], those focussed around upstream technologies are exemplary in doing this in that they take what to many participants is an invisible issue - a non-issue - and create a problem, ex nihilo. In doing so they not only construct a problem to be solved, but a group of citizens who are to perform their concerns in certain ways. This feature of public engagement with nanotechnology - and the impact that this creative process has on resulting public debate and wider discourses - remains, if not exactly a challenge to be overcome, a key aspect of the role of social science to be reflected upon'.

This opens several questions regarding measuring the amount of public trust in nanotechnology. First of all, one can question whether the very use of the concept of trust contributes to make the structures of the approach to public understanding fixed and inert. Many of the answers given in surveys are so open and flexible that they do not provide a useful material for helping to make good decisions based upon people's well-reflected opinions.

On this background I argue that there is a connection between how 'trust' is framed and understood-implicitly and explicitly_in upstream engagement, and the lack of ability of establishing a clear understanding of the role and function of this engagement.

Further I argue that this understanding of trust can be traced in existing literature on the concept of trust it self. If 'trust' is supposed to remain an analytical tool in establishing a social robust development of nanotechnology, I therefore suggest an approach where 'trust' must initially be seen in the context of establishing an understanding of where the 'shared questions' or conflict points are to be found. Only in this way it is possible to see emerging technologies as a part of emerging relationship of trust or distrust.

But this problem is not only traced in social research applying trust in their analyses. Also in 
philosophical accounts of trust there is a restricted understanding of what relationality means for understanding mechanism of trust in emerging technologies.

\section{Problems with Conventional Approaches towards Trust: The Question of Relationality}

The main reason is that the studies do not reflect relational aspects underlying potential trust involved. Most theories on trust agree that trust is a relational concept [14]. Russel Hardin (Hardin [18], 10) assumes that trust is a kind of evaluation following the scheme of a three-part relation: A trusts B to do X. This would be quite clear if we were dealing with a situation where A trusts that $\mathrm{B}$ will give back the money he borrowed. Or that I trust the hospital to give me the best treatment possible. Although the relationships involved are very different-on one hand a person, on the other an institution - what the trust evaluations have in common, is that the relationships involved are assumed as the basis for the evaluation. Actions and choices are likely to take place following our evaluation of trust and distrust, and if they do not, this could still be enlightening for our understanding of the relationship: A wife can say that she trusts her husband, while at the same time acting as if she didn't. And although I am afraid that my plane will crash, I do eventually board the plane, every time. How would we understand my ambiguity towards flying compared to someone who actually refuses to enter any plane? It seems clear that our understanding of the quality of the trust involved very much relies upon understanding the full context of the relationship, as situations where actions are or are not being made.

Now, the surveys mentioned above follow the same scheme for exploring trust in nanotechnology. My claim is that they fail to do so. This is not mainly because nanotechnology is an emerging technology and therefore a relationship-to-come. Many analyses and evaluations on trust involve relationships with unknown people or institutions as the basis for future interaction. The difference between these evaluations and those of nanotechnology, is that it is not clear to which extent the public's relationship with nanotechnology can be said to be a relationship at all. This is due both to the "forced" relationship mentioned above, that questions are being posed that might be irrelevant for the respondents. It is clear that we would not evaluate A's trust in some person on the other side of the globe unless we assumed that they would somehow interact with each other. And we would certainly not try to understand the mechanisms behind the distrust in the French government by studying the motivations for distrust of a citizen of Sweden being remote from the conflict.

But this is of course difficult to avoid completely as long as we are dealing with upstream engagement. The main problem is that as long as 'nanotechnology' remains unproblematized as a concept, it is not clear whether we are talking about an entity that can become an object of trust or distrust in terms of action or non-action. It is not enough to try to avoid the abstraction caused by unfamiliarity by presenting people for products 'close to everyday life' (Gaskell et al. [10]:21). Given that we do not know the substantiality of the concept nanotechnology or its future in regulatory term, we cannot know whether our measurements are actually referring to a relevant problem. The relationship between nanotechnology and the public remains vague and it is also difficult to demonstrate what the term nanotechnology relates to. Whereas the studies shown above focus on enriching our understanding as if the entities of the relationship were given - that of nanotechnology and the publicby mapping attitudes and motivations for trust in this particular relation, the problem, as I see it, lies in understanding how it is or becomes a relation in the first place, if at all. That is, whether it is a relation, how this relation emerges and how the establishing of the relation influences upon trust.

Surprisingly, this approach - to problematize the relationality of trust relationships-does not find support in any of those writings on trust that have shifting relationships due to technological change as their central topic.

This is mainly due to two factors. Firstly, that studies on trust base their research upon experience and therefore well-established relations or conflicts. Then there is no reason to problematize the scheme according to which the analysis is conducted, because the relationship is there and we can try to predict trust or distrust in similar situations by learning from the experience of the previous ones. Secondly, there are restrictions in the very theories of trust, because many of them tend to conceptualize trust around interpersonal relations. Trust is seen as evaluations of inter- 
personal probabilities in which 'an agent assesses that another agent or group of agents will perform a particular action' [9]. Thus trust is, as Luhmann sees it, an answer to the problem of coping with the freedom of others [29].

This implies that 'trust' is only seen in relation to purely human interactions, and interaction between humans and other entities like institutions or technologies are problematic or even conceptually rejected as possible trust relationships (Luhmann [28]:102, Hardin [18]). But then it is not so much about the phenomenon it self as of how theory is framing it.

Similarly, trust in 'nanotechnology' would also be problematic according to some definitions of trust. Since trust is sometimes assumed to be a kind of reflexive evaluation that excludes attitudes, prejudices, emotions or vague assumptions, it could easily be considered flawed already from the beginning to study 'trust' in the light of public attitudes at all. But most importantly, nanotechnology is not a human being, nor an institution, and it would therefore be difficult to talk about trust in relation with nanotechnologies in the first place, if some theories were to be followed. Then of course one could say that by 'nanotechnology' one actually means the experts. In Giddens approach to trust, the central claim is that modernity implies a shift from stable and wellestablished, to floating situations and relations, that are impossible to handle in terms of our own knowledge. Therefore, trust is following our lack of knowledge. Giddens calls this a "leap of faith", actively invested in expert systems of autonomous, reflexive individuals [12].

But even if we accept Giddens' leap, the concept trust remains inter-personal. Like Andreas Kaminski points out in his doctoral thesis, one can question whether Giddens' distinction of trust in persons and trust in abstract systems really makes a difference, because all in all, trust in abstract systems is trust in experts, and then we are back to trust in persons [23].

A second problem is that Giddens and others associate 'trust' to 'knowledge' in a way that excludes aspects of irrationality or other motivation grounds for trust (Grimen [14]:23, Hardin [18]). When trust is uniquely understood in relation with rational evaluation it will-ironically_lead back to the deficit model when applied on public understanding of technology. Then the grounds for involving trust in the first place - following the line of Brian Wynnebe undermined by trust it self.

If one accepted a claim that trusting nanotechnology means in fact trusting the experts of nanotechnology, or even more general, the expert community and the authorities, there would be no reason for challenging the scheme A trusts B with regards to X. But if trust is supposed to help us predicting possible controversies with nanotechnology, is it enough to stick to such a scheme, as if nanotechnology is something we will necessary going to interact with?

The example of Magic Nano indicates that this is not necessarily the case.

Despite which of the assumptions regarding the future of the concept 'nanotechnology' that will prevail, it leads us to pose certain necessary questions about the object of our trust analysis: Can you trust experts regarding something you are made unaware of, something that you don't know about or that doesn't even exist?

Regardless of the substantiality of the concept of nanotechnology, it is possible to imagine that nanotechnology will not lead to controversies, despite that there are negative attitudes towards it, and regardless of the possible harm caused by nanotechnological products. This is not the same as acceptance.

This raises conceptual challenges regarding the concept of trust and the scheme according to which surveys on trust are conducted. Examples such as MagicNano threatens to undermine the very foundation of what people express trust or distrust in. Thus the value of early engagement in nanotechnology can be severely reduced, firstly because the control one has over public attitudes in reality is lacking due to the way the technology is implemented in society. But more importantly, it fails to provide 'social robust' knowledge, because it is only measuring the degree of acceptance. Distrust will not lead to lay influence on the technology if the easiest way out of a controverse is to change its name.

Although all of these factors are-or at least might be - relevant, they are not sufficient to understand the basic mechanisms that make distrust and trust appear in real situations. What we do not know yet is where distrust could arise in relation to nanotechnology.

My claim is therefore that surveys on trust in emerging technologies like nanotechnology call for a supplementary study on the character of the technology in question as an object of trust. How can the 
object in question tell us something about the possible relations involved in future actions or non-actions taken towards novel technologies?

In most existing literature on lay people's attitudes towards new technologies, the main focus is usually on people's motives for trust or distrust, or trust is being captured although it remains unclear whether the expression of trust is a result of a certain framing of the survey, or whether it will eventually lead to precautions or actions of distrust being taken, such as public protests, political resistance or simply commercial boycott. But whereas this has an obvious relevance in already established conflicts (actions are being taken, a relation is established, and the motives determine the action), it is not obvious that the same is the case for emerging fields where even the object in question is undetermined or at least unclear. Rather, it is reasonable to believe that a continued focus of this kind creates blind zones in the social research approach.

The concepts are not developed through an understanding of empirically based relations that show how the motivations or attitudes actually lead to trust or distrust through action. Therefore, in order to maintain an analytical role in social research on emerging technologies, trust should be seen the light of two concepts: prediction and precaution. Prediction because the overall ambition of analyses on trust in emerging technologies should be to some extent to predict controverses that might arise. Precaution, because when clear relations or potential controversies are missing or not yet identified, a search for potential conflict points would help to identify and to clarify such relations.

\section{Prediction of Trust in Social Systems}

A problem with many theories on trust is the confusion regarding what we can actually have trust in. If empirical observations of trust leads to an essentialist understanding of the phenomenon, 'trust' becomes determinate for our understanding of relations rather than enlightening. In the case of nanotechnology, 'trust' would fail to fullfill its potential if by 'nanotechnology' we simply understood an indetermined set of 'experts'. Similarly, studies have shown how social research adopts the structures of previous experiences in evaluating new problems. If you assume for example that nanotechnology is like GM, as Sandler and Kay claim has been the case with early public engagement with nanotechnology [39], it forms the discourse in a way that might not provide discussions that are relevant to the object in question.

It would not be possible to analyse all the relevant factors that are decisive for acts of trust and distrust in the future if through the lenses of 'trust' we would not have the opportunity to taken into consideration the co-production between the lay public and the technology developers. With the concept of coproduction, one assumes that scientific achievements in society consist both of social as well as natural orders. Thus, in order to understand how technological entities function in the world,

'one has to ask how diverse actors use and understand the concept, how it is articulated through formal and informal practices, where and by whom it is contested, and how it reasserts itself in the face of challenges to its integrity or meaning' (Jasanoff [19]:19).

These variations in the understanding and use of a concept however are not taken into account by survey research, and yet they are quite decisive for our understanding of how technology is actually shaped and conceived in society. Also in the context of 'trust' this is an approach that would often fail to win recognition. Again this is due to the common attitude that 'trust' appears between human beings. You can rely on a technology, but only trust the experts. ${ }^{4}$ Therefore studies on trust are easily forced to accept any relation given to them, because it has not been seen as a relevant question to challenge them. If we trust a technology and accept the technology as an object of trust, it is only because we trust the people who are responsible for it. Therefore we too easily accept 'nanotechnology' as a given representative for its developers, although this distinction fails to see that there are many factors that overlap and interact indistinctively with each other in creating what we see as the social meaning of 'nanotechnology' that is presented to us.

Therefore, nanotechnology should be seen in the context of being a social system, ${ }^{5}$ as an indistinct set

\footnotetext{
${ }^{4}$ For further reading about the difference between familiarity, confidence, reliability and trust, see [14], [18], [28] and [12].

"I use the term "social system" [soziale Systeme] from Luhmann's book 'Soziale Systeme' [27]. Although this concept can easily be understood in relation with trust, he does not make this connection himself.
} 
of factors such as experts, institutions, reputations, public communication, governmental policies, artefacts and a whole range of possible relevant aspects for the framing of nanotechnologies and the public reception of them. There are several reasons for considering it in this way: Firstly, nanotechnology is not dismissed as an object of trust according to certain definitions on trust. Secondly, studies on trust can not assume relations between technology and the public as relations between indistinct "experts" and the public. And thirdly, this would change the focus of trust studies, and provide a new analytical function to the concept: Given that many social systems are vague and difficult to grasp when it comes to isolate their components, a study would initially have to focus on analyzing the system in question in terms of being an object of trust; to which extent it is likely to be trusted, in which way distrust might arise, and why this might happen. Then it is also easier to incorporate other dimensions and aspects of trust, such as motivations, in a relevant way. Thus, 'trust' can be used as an analytical tool for understanding how social entities are established in public as meaningful object we can relate to.

I will give an example of what this means: If I were in a store, faced with the choice between a GM-tomato and a non-GM-tomato, it would be a simplification just to analyze my final choice as an expression of trust in GM or not and what my motivation for this choice would be. Of course this is interesting when GM is already present in the store and the GMproducers observe that I and several others choose to avoid their products. But then we already have a situation where my actions can be understood through my motivations and alternative actions for technology developers can be made possible through a further understanding of these motivations. But as many studies on trust and distrust start here, namely, where such conflicts are already established, the situation is different with emerging technologies where even the concept itself is diffuse regarding its content and future significance. In such situations, understanding trust will have to signify an understanding of how an object of trust becomes an object of trust. Or, in certain situations, whether something can even claim the right to be called an object of trust at all. Then we realize that something as simple as choosing a tomato in a store is the result of several aspects regarding trust that are not included in a study on my motivations for action.

My action, or my precaution against choosing a GM-tomato, is the result first and foremost of having the choice to choose otherwise. The less available non-GM-tomatoes are, the stronger my attitude against GM must be for me to try to get alternatives. The attitude itself is shaped by an indistinct mixture of information, prejudices, trust in experts, NGO's and authorities, my own political standings, religious beliefs, etc. It would probably not be possible to understand each of these factors to a full extent. Nor is it possible to understand them isolated from each other. GM is not a thing, nor an object, but a combination of techniques, content, people, visions, political regulations and communication. Thus it would not be adequate to reduce our understanding of GM to only one or some of these factors. GM is also the totality of its factors, and in relational terms mechanism of trust and distrust should be understood in relation with this totality.

My claim is that 'trust' might provide better grounds for understanding how such entities emerge into relations, because by understanding a social entity, whether it is just a hype or something we actually relate to, involve qualitiative differences that have relevance for how they appear in the 'real' world. That is why understanding such entities as 'social systems' is a viable approach.

For example, analyzing visions of nanotechnology, by means of epistemology, views on nature, etc., is relevant for the discourse on trust, because one can find compatibility or non-compatibility concerning the views on nature and science as compared to those of the consumer. [8, 43] But this relationshipbetween the vision and the individual person - cannot alone form the basis of a relationship that provides a meaningful knowledge of possible precautions.

That is, although earlier experience shows how just the term 'GM' is decisive for people's general attitudes towards all the various applications related to GM, and therefore also relevant for understanding the motivations of taking precautions or not, this image itself only becomes an issue when the label relates to something where precautions are possible in the first place. If the term nanotechnology is shown to be nothing but a buzzword, and the individual is ignorant of what nanotechnology means, we would not be able to distinguish this situation from one in 
which an environmental activist feels nanotechnology is 'the new GM', if the attitudes or motivations between them were principally the same. But what does this mean for the concept of trust itself? Would 'trust' be an empty concept if it could not lead to action? And how do we distinguish qualitatively between various beliefs, motivations or emotions of trust?

The concept of 'precaution' is particularly important in evaluating emerging social systems. The reason is that analyzing where and how precautions can be taken, draws a first sketch of an emerging relation involving trust, and problematizes this relation at the same time:

In his account on trust, Jon Elster writes about so called 'quasi-emotions' (Elster [7]:71). People can express certain feelings that do not lead to a subsequent action. For example, one can be upset about poverty in the Third World, without there being even the slightest movement in one's wallet. Elster calls this sentimentality. In principle, a sentimental person would have exactly the same feelings as a person who would donate some money or as a person who would devote his entire life to fighting poverty. But there are obvious differences between the three people in this matter that are so important that they would make any analysis which did not incorporate them irrelevant. In order to understand emotions, it is not enough to try to catch and determine the experience of them; they must be seen in context with their outcome in possible actions, and in which respect emotions become determinate for relations. Distrust comes, as Pidgeon and Poortinga state in many shapes, some of which are good [37]. The utmost challenge to technology developers is when distrust manifests itself through active rejection. For social research, it can neither be a premise of the research that distrust is bad, nor should social research focus solely on mapping emotions or attitudes that are seen in relation to an unquestioned, given object. On what grounds do we determine what trust is? Elster quotes La Rochefoucauld, who once wrote that 'some people would have never fallen in love if they had never heard of love' (op.cit., 161). Using 'trust' uncritically in surveys provides the challenges that we give name to an expected feeling or attitude in people that probably would not have existed without our interference, or at least, would have had fewer behavioural manifestations. In a broader sense, regarding our own work, we would not pay sufficient attention to the role or significance of the concept in the first place. This does not mean that Elster's theory is encompassing all relevant aspects of trust. But his approach is of particularly interest in the field of public understanding of nanotechnology, because the focus on possible precautions makes it possible to make initial determinations of the relationship in question. Elster's focus on actions and precautions is of particular relevance in relation to such a complex and difficult notion as nanotechnology, because it forces relationships, or the lack of such relationships, to manifest themselves and thus makes further analysis in a somewhat vague and undefined landscape possible.

The inner qualities of trust are already difficult to sort out. Annette C. Baier, whose writings stand among the pioneer works in the literature on trust, has pointed to several characteristics that make trust so difficult to define, even in relationships that are familiar to us, such as those between individuals. As she puts it:

'Trust is one of those mental phenomena attention to which shows us the inadequacy of attempting to classify mental phenomena into the "cognitive", the "affective" and the "conative". Trust, if it is any of these, is all three. It has its special "feel", most easily acknowledged when it is missed, say, when one moves from a friendly "safe" neighborhood to a tense insecure one. It has its (usually implicit) belief component, belief in the trusted's goodwill and competence, which then grounds the willingness to be or remain within the trusted's power in a way the distrustful are not, and to give the trusted distrustful are not, and to give the trusted discretionary powers in matters of concern to us. When we trust, we accept vulnerability to others' ([1]:132).

She characterizes trust and distrust as feelings that are 'like what Hume called 'impressions of reflexion', feeling responses to how we take our situation to be.' (op.cit., 131) But what exactly is our situation when confronted with nanotechnology? The complexity of the notion of trust alone shows us that we have insufficient knowledge to provide rich and satisfying answers. We do not know whether the trusted object is good or bad. Subsequently, we do not know whether trust is good or bad. We know little about the strength and character of the opinions expressed, 
and we do not know at all to which extent such opinions can manifest themselves into action. This is perhaps not surprising, as we are-despite there being products already on the market - still talking about an emerging technology. But still, there are some aspects we should look for, aspects that are in accordance with what we already know about trust and distrust in technologies.

For example we know that although a shift has occurred in social research regarding a lack of trust versus a lack of information, it is not true that a lack of trust can always be explained by the values and attitudes of the public involved. Nor can trust and distrust be explained solely by the communication of information or the hyping through utopias and dystopias, creating optimistic or pessimistic 'imaginaries' in the lay public's minds. Although all of these factors are-or at least might be-relevant, they are not sufficient to understand the basic mechanisms that make distrust and trust appear in real situations. What we do not know yet is where distrust could arise in relation to nanotechnology. Both are important preconditions for understanding situations as locations for gaining socially robust knowledge, as well as for the general understanding of mechanisms of trust.

Using 'precautions' as the initial approach to understand social systems helps us identifying how relations appear, and to which extend and in which sense they involve trust. Thus it is possible to use 'trust' as an analytical tool for understanding social entities and how they interact upon each other, distinguishing between those who will not interact (images for example) and those who will.

This is important also for maintaining the important role of trust in social research, because it binds trust to empirical findings instead of normativity loosened from empirical grounds:

In a much quoted article on the concept of trust in risk regulation, Poortinga and Pidgeon [37] point to the important observation that although trust is conceived as an important aspect of the relationship between the public and technology, it often remains unproblematized whether trust, as such, is something necessary and good. Through additional survey work, they outline the alternative notion of critical trust, which is meant to show that trust and distrust are complementary phenomena that often operate together in various combinations, and often for the goodfor technology as well as for the public. When people's motives for trust are the main focus, the answer is often that one has to strive for better conditions for trust. But then again it remains unproblematized what all this trust is good for in the first place. Poortinga and Pidgeon's point is enlightening in this respect, but it still remains an open question how trust and distrust operate, what forms them, and what kind of interests are the motivating factors behind their re-conceptualization.

The initial focus should therefore be likeliness to be trusted, so that trust and trustworthiness are not understood as a normative, that is, whether nanotechnology should be trusted or not, but as to whether it is implemented in a way that is likely or not likely to cause controversies. Only then the role and function of trust is properly reflected into the relation, and only then one could add other dimensions to the analysis, as to whether controversies, or the lack of them, should or should not have taken place. If you take a social system as given and analyse trust in relation with it, you might get the wrong answer because your understanding of the relation in question is wrong.

\section{Concluding Remarks}

Richard Jones has showed how difficult it is to make people have any relationship with a concept encompassing so many areas and applications, and thus, contrary to concrete applications or a nuclear factory, it is difficult to determine what this trust or distrust would actually be an expression of. Different levels or dimensions of trust, as the ones exemplified by Poortinga or by Wynne, can only be fully explored when the entire spectre of a relationship is clearly expressed. This has hardly been done, despite that already in 2003 there was a general attitude that nanotechnology was better thought of as a 'multifaceted and malleable group of technologies', difficult to associate to specific areas of application [44]. Despite this assumed ${ }^{6}$ early engagement in a field of technology which still remains largely unknown to the public, it is surprising to see how looking at the very conditions for involving lay people in a way that actually produces interaction is still missing. If this

\footnotetext{
${ }^{6}$ It is contested whether the social engagement work on nanotechnology has come in very early or too late. See for example: Mnyusiwalla et al. [32].
} 
were the case, it would have been natural to start with the term 'nanotechnology', to see whether it was to relate it with trust or distrust. A series of examples show how difficult this is.

I have tried to show how trust and trustworthiness can serve as analytical tools in social research on nanotechnology. In a situation where the object in question is still somewhat blurred even to the initiates and where we seemingly enter a landscape that is much more complex than what is usual in societal contexts where trust is at stake, a possible first approach would be to analyze the concept 'nanotechnology' in terms of its possible conflict points, in other words, where public precautions in terms of trust or distrust might appear. This is important simply to understand what we are talking about and in what respect it is useful to use the nano label when engaging the public. A further and full analysis of the trustworthiness of nanotechnology would eventually have to analyze other aspects of its trustworthiness, according to more traditional parameters, such as stakeholder aspects, risk aspects and the quality of regulatory work, all in close relation with the societal aspects of the 'imaginaries' of nanotechnology that will or will not eventually be established in the public when conclusively coined and shaped. Although many of these aspects are already established approaches within social research for enhancing public assent through cooperation, it nevertheless still remains an open question as to what extent they are sufficient if social research wants to enhance socially robust technology. The reason is that the concept 'nanotechnology' transgresses what we usually think of within institutional frames such as experts, authorities, risk analysis, etc. Public distrust in science can appear in all of these contexts, but it can also appear on grounds that are not captured by enhancing trustworthiness on these grounds. The large number of various stakeholders simply makes it impossible, and unforeseen factors can lead to actions of distrust. The concept 'nanotechnology' itself is one of them.

Open Access This article is distributed under the terms of the Creative Commons Attribution Noncommercial License which permits any noncommercial use, distribution, and reproduction in any medium, provided the original author(s) and source are credited.

\section{References}

1. Baier AC (1994) Trust and its vulnerabilities. In: Baier AC (ed) Moral prejudices. Harvard University Press, pp 130151

2. Barnett J, Carr A, Clift R (2006) Going public: risk, trust and public understandings of nanotechnology. In: Hunt G, Mehta MD (eds) Nanotechnology. Risk, ethics and law. Earthscan, London, pp 196-212

3. Beck U (1986) Risikogesellschaft. Auf dem Weg in eine andere Moderne. Suhrkamp Verlag, Frankfurt am Main

4. Cook KS, Hardin R, Levi M (2005) Cooperation without trust? Russel Sage Foundation, New York

5. Davies S, Kearnes MB, Macnaghten P (2010) Nanotechnology and public engagement: a new kind of (social) science? In: Kjølberg KL, Wickson F (eds) Nano meets macro: social perspectives on nanoscale sciences and technologies. Pan Stanford, Singapore, pp 405-423

6. Ebeling MFE (2008) Mediating uncertainty: communicating the financial risks of nanotechnologies. Sci Commun, p 29

7. Elster J (2007) Explaining social behaviour. Cambridge University Press

8. Ferrari A, Gammel S (eds) (2010) Visionen der Nanotechnologie. Akademische Verlagsgesellschaft, Heidelberg

9. Gambetta D (1988) Trust: making and breaking of cooperative relations. Blackwell, Oxford

10. Gaskell $\mathrm{G}$ et al (2010) Europeans and biotechnology in 2010. Winds of change? A report to the European Commission's Directorate-General for Research. October 2010. Retrieved November 14, 2010, from http://ec.europa. eu/public_opinion/archives/ebs/ebs_341_winds_en.pdf

11. Gibbons M (1999) Science's new social contract with society. Nature 402:81-84

12. Giddens A (1990) The consequences of modernity. Polity, Oxford

13. Gottweis H (1998) Governing molecules. The discursive politics of genetic engineering in Europe and the United States. Massachusetts Institute of Technology

14. Grimen H (2009) Hva er tillit. Universitetsforlaget, Oslo

15. Grove-White R, Macnaghten P, Mayer S, Wynne B (1997) Uncertain world: genetically modified organisms, food and public attitudes in Britain. Centre for the Study of Environmental Change, Lancaster University, Lancaster

16. Hampel J, Klinke A, Renn O (2000) Beyond'Red' hope and'Green' distrust. Public perception of genetic engineering in Germany. Politeia 16(60):68-82

17. Hardin R (1996) Trustworthiness. Ethics 107:26-42

18. Hardin R (2002) Trust and trustworthiness. Russel Sage Foundation, New York

19. Jasanoff S (2005) Designs on nature. Science and democracy in Europe and the United States. Princeton University Press, Princeton

20. Jones R (2008) When it pays to ask the public. Nat Nanotechnol 3:578-579

21. Kahan DM (2009) The evolution of risk perceptions. Nat Nanotechnol 4:705-706

22. Kahan DM, Braman D, Slovic P, Gastil J, Cohen G (2009) Cultural cognition of the risks and benefits of nanotechnology. Nat Nanotechnol 4:87-90 
23. Kaminski A (2010) Technik als Erwartung. Grundzüge einer allgemeinen Techniktheorie. Dissertation, Universität Darmstadt

24. Kearnes MB, Macnaghten P, Wildsen J (2006) Governing at the Nanoscale. People, policies and emerging technologies. Demos

25. Kearnes MB, Wynne B (2007) On nanotechnology and ambivalence: the politics of enthusiasm. NanoEthics $1: 131-142$

26. Klaessig F (2010) Nanotechnology: paradigm or bubble. Paper presented at the Second Annual Conference of the Society for the Study of Nanoscience and Emerging Technologies. Darmstadt, October

27. Luhmann N (1984) Soziale Systeme. Grundriss einer allgemeinen Theorie. Suhrkamp Verlag, Frankfurt

28. Luhmann N (1988) Familiarity, confidence, trust: problems and alternatives. In: Gambetta D (ed) Trust: making and breaking of cooperative relations. Basil Blackwell, Oxford

29. Luhmann N (2000) Vertrauen. Ein Mechanismus der Reproduktion sozialer Komplexität. Lucius \& Lucius, Stuttgart, 1968

30. Macnaghten PM, Kearnes MB, Wynne B (2005) Nanotechnology, governance, and public deliberation: what role for the social sciences? Sci Commun 27(2):268-291

31. Misztal BA (1996) Trust in modern socities. The search for the bases of social order. Polity, Cambridge

32. Mnyusiwalla A, Daar AS, Singer PA (2003) 'Mind the gap': science and ethics in nanotechnology. Nanotechnology 14:R9-R13

33. Nanotechbuzz.com (2006) No nano in MagicNano. Retrieved on November 15, 2010, from http:/www.nanotechbuzz.com/ 50226711/no_nano_in_magic_nano.php, may 27

34. Nowotny $\mathrm{H}^{-}(1999) \overline{-}$ The need for socially robust knowledge. T-A-Datenbank-Nachrichten, 3/4. Retrieved March 9, 2009, from http://www.itas.fzk.de/deu/tadn/tadn993/ nowo99a.htm, December
35. Nowotny H (2000) Re-thinking science. From reliable to socially robust knowledge. In: Nowotny H, Weiss M (eds) Jahrbuch 2000 des Collegium Helveticum. vdf, Zürich, pp 221-244

36. Nowotny H, Scott P, Gibbons M (2001) Re-thinking science: knowledge and the public in an age of uncertainty. Polity, Cambridge

37. Poortinga W, Pidgeon NF (2003) Exploring the dimensionality of trust in risk regulation. Risk Anal 23:5

38. Royal Society and Royal Academy of Engineering (2004) Nanoscience and nanotechnologies: opportunities and uncertainties. Royal Society Policy Document, 19/04

39. Sandler R, Kay WD (2006) The GMO-Nanotech (Dis) Analogy. Technol Soc 26:57-62

40. Satterfield T, Kandlikar M, Beaudrie CEH, Conti J, Harthorn BH (2009) Anticipating the perceived risk of nanotechnologies. Nat Nanotechnol 4:752-758

41. Siegrist M, Earle TC, Gutscher H (2003) Test of a trust and confidence model in the applied context of Electromagnetic Field (EMF) risks. Risk Anal 23(4):705-716

42. Toumey C (2007) Rules of engagement. Nat Nanotechnol 2:386-387

43. Wickson F (2008) Narratives of nature and nanotechnology. Nat Nanotechnol 3:313-315

44. Wood S, Jones R, Geldart A (2003) Social and economic challenges of nanotechnology. Economic and Social Research Council, Swindon

45. Wynne B (1992) Misunderstood misunderstandings. In: Irwin A, Wynne B (eds) Misunderstanding science: the public reconstruction of science and technology. Cambridge University Press, Cambridge

46. Wynne B (1995) The public understanding of science. In: Jasanoff $\mathrm{S}$ et al (eds) Handbook of science and technology studies. Sage, Thousand Oaks, California, pp 361-388

47. Wynne B (1996) May the sheep safely graze? In: Lash S, Szerszynski B, Wynne B (eds) Risk, environment and modernity: towards a new ecology. Sage Publications, London 